\title{
Master's Graduates as State-Licensed Psychotherapists, Both a Challenge and an Opportunity: Practical University Teaching Concepts in Clinical Psychology
}

\author{
Marcel Wilhelm ${ }^{\mathrm{a}}$ Winfried Rief ${ }^{\mathrm{a}} \quad$ Anke Haberkamp $^{\mathrm{a}}$ Pia von Blanckenburg ${ }^{\mathrm{a}}$ \\ Julia Anna Glombiewski ${ }^{b}$

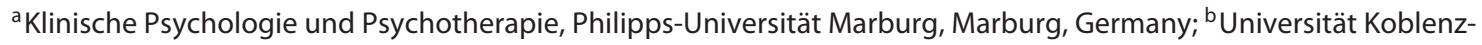 \\ Landau, Koblenz-Landau, Germany
}

\section{Keywords}

Application-oriented university teaching · Psychotherapy master's degree · Approbation study · Job-qualifying work · Intervention training $\cdot$ Case seminar

\begin{abstract}
Psychotherapeutic training in Germany is about to be changed soon: master's graduates in clinical psychology will be able to become state-licensed psychotherapists. It is therefore mandatory to teach basic psychotherapeutic skills at the universities. This article presents examples of application-oriented courses in clinical psychology, which have been tried and tested at the Philipps University of Marburg for years. During the practical exercises "Interventions in practice 1 and $2^{\prime \prime}$, students gain initial experiences with psychotherapeutic techniques on personally relevant problems. In the case seminar, the students apply their acquired skills to treat an actual outpatient case, while translating basic psychological knowledge into an individualized treatment plan. The seminar "Different approaches to psychotherapy in practice" offers the opportunity to explore 6 different patients coming from a variety of treatment settings. The courses are evaluated regularly. An overview of cumulated evaluations shows a high degree of student satisfaction with the course concepts. The described courses meet several requirements of the new licensing regulations, especially regarding job-qualifying and self-reflection. Necessary
\end{abstract}

adjustments and additional requirements are discussed, and possible solutions are presented accordingly. If the licensing regulations are implemented as demanded, receiving a state license after the master's degree seems justified.

(c) 2021 S. Karger AG, Basel

\section{Studium zur Psychotherapie-Approbation als Herausforderung und Chance: Praktische Hochschullehrkonzepte in der klinischen Psychologie und Psychotherapie}

\section{Schlüsselwörter}

Anwendungsorientierte Hochschullehre .

Psychotherapiemaster · Approbationsstudium .

Berufsqualifizierende Tätigkeit .

Interventionspraktikum · Fallseminar

\section{Zusammenfassung}

Die Psychotherapiereform verändert die Ausbildung von Psychotherapeutinnen und -therapeuten in Deutschland: Zukünftig sollen klinisch-psychologische Masterstudiengänge mit einer staatlichen Approbationsprüfung in Psychotherapie abgeschlossen werden. Die hochschulische Lehre muss entsprechend psychotherapeutische Basisfertigkeiten praktisch vermitteln. Dieser Artikel stellt Modelle praxisorientierter Lehrveranstaltungen der klin- 
ischen Psychologie der Philipps-Universität Marburg vor die größtenteils seit Jahren erprobt sind. Bei den praktischen Übungen "Interventionspraktikum 1 und 2" machen Studierende erste Erfahrungen mit therapeutischen Techniken an persönlich relevanten Problemen. Im Fallseminar wird das Gelernte an einem Fall aus der ambulanten Versorgung vertieft und eine Translation des Grundlagenwissens auf einen individualisierten Behandlungsplan gefördert. Während hier mit einem Fall intensiv gearbeitet wird, bietet das Seminar "Unterschiedliche Ansätze der Psychotherapie in der Praxis" die Gelegenheit, 6 verschiedene Fälle aus wechselnden Behandlungssettings nach vorgegebenen Gruppenthemen zu explorieren und Unterschiede herauszuarbeiten. Die Veranstaltungen werden regelmäßig evaluiert. Eine Übersicht über verschiedene Lehrpersonen hinweg zeigt eine sehr hohe Zufriedenheit der Studierenden mit den Veranstaltungskonzepten. Die bestehenden Veranstaltungen setzen viele Forderungen der neuen Approbationsordnung um, v.a. im Hinblick auf die berufsqualifizierende Tätigkeit II und III sowie die Selbstreflexion. Notwendige Anpassungen sowie zusätzliche Anforderungen an die Hochschullehre werden diskutiert und Lösungsvorschläge gemacht. Werden die Anforderungen der Approbationsordnung entsprechend umgesetzt, scheint Approbation im Anschluss an das Masterstudium gerechtfertigt.

(c) 2020 S. Karger AG, Basel

\section{Introduction}

The forthcoming changes in the training of psychotherapists mean, among other things, the conversion of existing psychology programs to a course of study leading to a state psychotherapy license. Many university institutes are therefore aiming for a 3-year polyvalent bachelor's degree in psychology and a 2-year master's degree program in clinical psychology and psychotherapy, which concludes with a state psychotherapeutic examination. If the exam is passed, the license is conferred directly. Although further training is required, for example, to work in a private practice or for entry into the medical register, psychotherapists receive a Behandlungserlaubnis (license to treat) immediately after completing their studies. This makes it essential for university teaching to have a high practical component.

The licensing requirements for psychotherapists (PsychThApprO) approved on February 14, 2020, by the Bundesrat [Bundesgesetzblatt, 2020] determine the content to be taught in university courses so that a subsequent license can be issued to practice psychotherapy according to $\$ 2(1)(1)$ of the Psychotherapists Act (PsychThG). The course of study should enable students to pursue further training and continuing education in- stead of requiring postgraduate training, as was the case in the past. Lectures, practical exercises, and seminars (including advanced seminars) are suggested as possible courses. While lectures and seminars serve above all to convey and deepen scientific and methodological knowledge, students should also gain the necessary knowledge and skills in practical exercises, and know how to apply them in practice.

Appropriate application-oriented courses must be used to prepare university students for their practical work. However, the task of psychology studies in Germany, which has been very broad up to now, has been primarily to provide theoretical and content-related education. Practical courses in clinical psychology have hitherto not been compulsory. Practical skills were often taught only in postgraduate training as a psychological psychotherapist. But university courses that are as practical as possible have already helped to bridge the gap between basic (clinical) psychological principles and the reality of psychotherapeutic practice. Such formats have been conceived, tested, and further developed in recent years at the Philipps University of Marburg, where the first experience with such courses goes back decades. This experience may be beneficial in the restructuring of university teaching, so we describe selected practical teaching concepts in the present article.

According to the recommendations of the Deutsche Gesellschaft für Psychologie (DGP, German Society for Psychology) for quality assurance in studying and teaching psychology, university teaching should be oriented toward psychological research findings [Spinath et al., 2018]. When students learn something new, a practical examination of the content is important in order to link it to the student's existing knowledge and long-term memory, as well as to improve recall for later transfer tasks [Schmidt and Tippelt, 2005; Reinmann and Mandl, 2006]. The transfer to practice of the skills learned during study for the psychotherapeutic profession poses a major challenge: it is more successful if the situations in study and in practical application are as similar as possible [Tonhäuser and Büker, 2016]. It is also recommended to actively discuss transfer goals and/or obstacles to transfer and thus to promote the students' self-efficacy regarding transfer to their professional work [Solga et al., 2011]. For German university teaching in the future master of psychotherapy programs, this means specifically that it should be as practical as possible and as close as possible to psychotherapeutic work on the job. The smaller the difference between teaching and application, the easier it should be for the students to apply what they have learned and to overcome obstacles to transfer. A license to practice psychotherapy can only be justified if this is successful.
2

Verhaltenstherapie DOI: $10.1159 / 000508273$
Wilhelm/Rief/Haberkamp/ von Blanckenburg/Glombiewski 


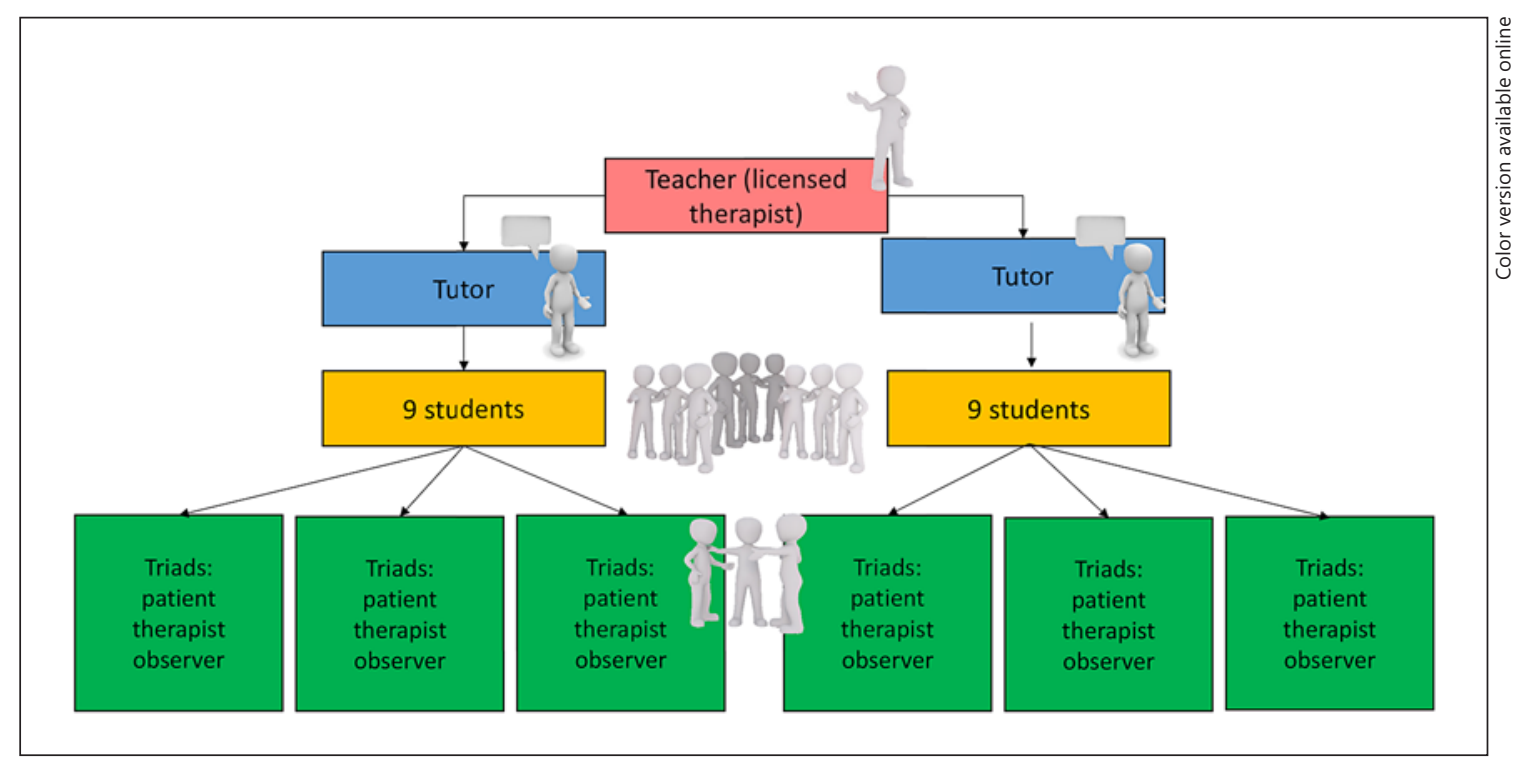

Fig. 1. Supervisory structure of IP1: 18 students are divided into two small groups. Each small group is supervised by a tutor. Two small groups are supervised by a lecturer.

In addition to the courses' structural orientation to the students' intended profession, they should be fine-tuned, incorporating student feedback, current clinical research findings, and new therapeutic interventions. One of the principal goals should be to enable students to apply in practice the theoretical content that they have previously learned (e.g., knowledge about disorders, evidence-based treatment recommendations, description and modification of relevant psychological processes). For example, role playing gives the students their first experience in directing psychotherapeutic conversations as well as in the selection, planning, and implementation of therapeutic techniques. These experiences are then deepened in courses that have direct patient contact that is as diverse as possible. This is exactly what the PsychThApprO provides for in a master's degree program, in the form of "berufsqualifizierende Tätigkeit” (BQT, practice-oriented training).

Some practice-oriented courses are described below, associated teaching evaluations are presented, and a comparison with the requirements of the PsychThApprO as well as specific suggestions for adaptation are supplied.

\section{Examples of Practical Teaching}

\section{Intervention in Practice 1}

Organizational. Intervention in Practice 1 (IP1) is a 1-week block course in which basic techniques of behavioral therapy (for adults) are discussed and tested. The main point for the students is to try out the therapeutic role. For IP1, the students are divided into triads, which allows them to take the roles of therapist, patient, and observer. Students are encouraged to bring in a relevant, current, and clearly defined problem that they would like to work on for a week. The teaching licensed therapist participates in the selection of problems and makes sure that they are not too distressing (e.g., relationship or family problems) or serious, pathological problems. Interactional problems (e.g., difficulties in expressing one's needs/opinion/saying "no") or subclinical, specific anxieties are suitable (e.g., social anxieties or fear of heights, driving, spiders, etc.). Thus, IP1 also includes aspects of self-reflection. The students are assigned to therapeutic dyads, and this structure remains for the entire week in order to facilitate more in-depth work on the problem.

The students form groups of nine, which are led by student tutors. The division into small groups makes it easier to offer all group members a sufficient opportunity to give feedback and to discuss and modify problems of implementation in a timely manner. The course includes a script that summarizes the theory, procedure, and common difficulties of various interventions. A licensed teacher leads two small groups, each of which has a student tutor (Fig. 1). The course comprises 3 semester hours per week. The students get a brief theoretical introduction to the techniques to be performed, based on the script. During the exercises, the triads are assisted by the tutors and teachers. This allows targeted feedback and, if necessary, assistance with the techniques in question. The teachers provide supervision by discussing problems that arise with the tutors during the 2-hour lunch break and in the evening. In order to avoid excessive pressure to perform during the exercises, the students prepare a report after 


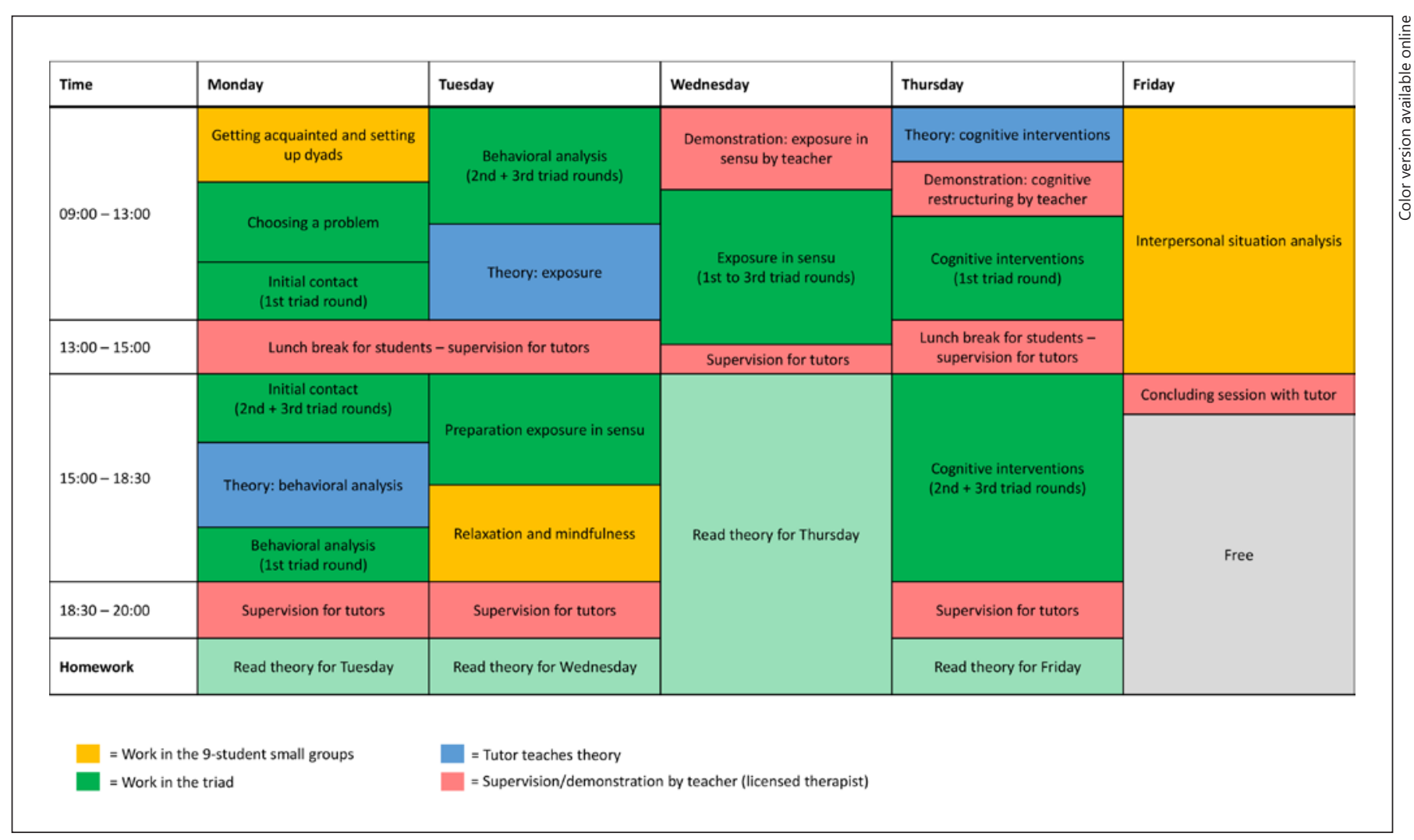

Fig. 2. Schedule: Intervention in Practice 1.

the IP week as a seminar assignment, in which they critically reflect on the individual topics and exercises. Seminar participation is not graded.

Content. Figure 2 shows the prototypical schedule of the IP, with its content modules. In the first discussion, the problem students have brought with them is explored. In the behavioral analysis block, this problem is assessed in role playing based on a specific situation in a SORCK schema at the microlevel, before the problem is classified at the macrolevel. Then the intended target behavior in one of these critical situations is imagined as part of an exposure in sensu. In the last block, the first cognitive interventions (cognitive restructuring, Socratic dialogue, pro/contra lists, etc.) are selected and applied to the problem of the person assigned. Two additional blocks in the small group setting complete the week: relaxation procedures and interpersonal situation analysis (see CBASP) [McCullough, 2000; Brakemeier and Normann, 2012], in which an index patient agrees to work in group therapy on the problem they brought with them and students converge upon the desired behavior in role playing.

\section{Case Seminar}

Organizational. In the case seminar, 15 students work on a case as a therapeutic team under the guidance of a licensed teacher. A patient from outpatient care is invited to each class for this purpose. The case seminar proceeds throughout the semester or in a block (Monday to Friday, all day) and comprises 3 semester hours. The seminar assignments include a case report (application for longterm therapy + course of treatment, with the possibility to obtain additional points through further work, such as self-reflection, effectiveness of individual interventions; max. 8 pages). Since the therapeutic techniques learned in IP1 are intended to be applied and deepened in the case seminar, successful participation in the IP is a prerequisite for participation in the seminar.

Content. The content varies considerably depending on the case. The seminar is oriented towards the key points of probational sessions (anamnesis, differential diagnosis, biography). The behavioral analysis practiced in IP1 is deepened. In the subsequent intervention phase, the indicated evidence-based and guideline-oriented interventions are jointly selected, planned and, if possible, carried out independently under supervision. The licensed teacher acts as therapeutic model, supervisor, support, or as part of the therapeutic team. Discussion and feedback rounds, group work, journal clubs, introductory presentations, and much more are used for preparation and follow-up as well as for the transfer of theoretical content. If the patient being discussed in the case seminar is taking psychotropic drugs, for example, individual stu- 


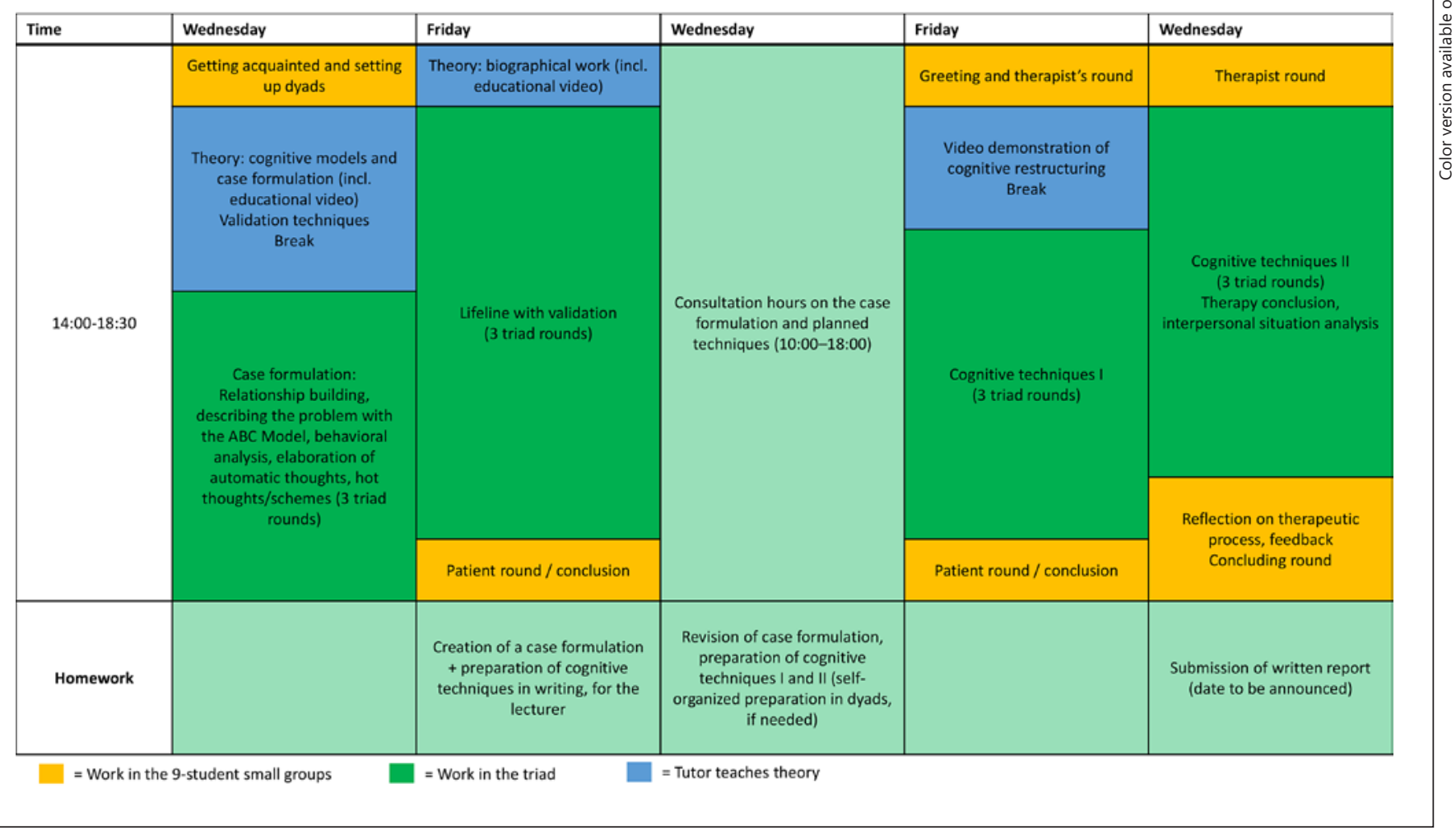

Fig. 3. Schedule: Intervention in Practice 2.

dents assemble basic information such as indication and mode of action, and communicate it to the group. The individualized configuration of the seminar offers a very detailed insight into therapeutic work and gives all students the opportunity to have direct patient contact. Social phobia is a particularly well-suited disorder for the case seminar, since working with the group can be an intervention in itself. But other anxiety or obsessive-compulsive disorders are also suitable, especially in the block format, in order to perform concentrated exposures. Eating disorders may also be an option, for example by using the group for close-knit mealtime support of the patient. It is also possible to deal meaningfully with social competence deficits, e.g., through role playing excercises. The semester format is also useful to treat depressive symptoms, for example with cognitive techniques. All patients who are eligible for outpatient treatment are in principle eligible for the case seminar.

\section{Intervention in Practice 2}

Organizational. Intervention in Practice 2 (IP2) functions according to the same triad principle as IP1 and also deals with techniques of adult therapy. The students form groups of 12; they are led by tutors who this time are students in advanced postgraduate psychotherapeutic training at the Institut für Psychotherapieausbildung (Insti- tute for Psychotherapy Training) in Marburg. Here too, there are two groups instructed by licensed psychotherapists (for 2 semester hours) (Fig. 1). The temporal structure is equalized by comparison with IP1 and is therefore more oriented towards outpatient care (1-2 appointments/week, Fig. 3), which enables students to prepare more thoroughly for their therapeutic role. Whereas single conversation sequences in IP1 were only about 10-15 min long, IP2, with triad rounds of about $50 \mathrm{~min}$, offers more freedom for individual configurations, similar to an outpatient therapy session. Here too, the students are encouraged to bring in a problem of their own. The close supervision by active therapists makes possible a much broader spectrum in the selection of problems (family/ relationship conflicts, procrastination, subclinical symptoms), than IP1. By analogy with IP1, the seminar requires a written report, which primarily involves self-reflection about the therapeutic experience.

Content. At the first session, the problem is first explored as part of an initial consultation; then a case formulation is created based on the expanded basic case formulation model according to Persons [2008]. Worksheets (e.g., the ABC model) [Ellis, 1962] can be helpful for this. The Lifeline from Narrative Exposure Therapy [Schauer et al., 2011] is used in the second session to record the individual's life story. Students playing the role of the pa- 
tient can decide which key life events they would like to introduce in the form of "stones and flowers"; as in the IPs overall, there is no obligation to provide a complete biography. The therapeutic skills are further developed by a focus in the triad exercises on validation techniques (dialectical-behavioral therapy) [Linehan, 1993]. In IP2, too, the students are closely supported in performing the triad exercises, receiving help and/or feedback. The students then appear individually for the third session, which is a 30-min supervisory consultation with a licensed teacher or tutors who are in psychotherapeutic training. Various techniques for working on the problem are discussed in advance; these could be used in the remaining two sessions. This keeps the range of techniques very open and enables individual selection, planning, and implementation depending on the requirements of the problem and the interests of the particular students. The accompanying script suggests cognitive interventions [e.g., according to Leahy, 2017], in addition to techniques from acceptance and commitment therapy [Hayes et al., 2004], dialectical-behavioral therapy [Linehan, 1993], or "chair exercises" for emotion-focused work [Greenberg, 2004]. IP2 is also open to other procedures, such as aspects of psychodynamic or systemic therapy.

\section{Different Approaches to Psychotherapy in Practice}

Organizational. The semester seminar comprises 2 semester hours. It usually runs on 4 tracks ( 4 seminars with 30 students each, occurring simultaneously). The 30 students alternate in the seminar setting or all four seminars take place at once (a total of 120 students) in the lecture hall. Each seminar is run by a teacher. The students' task is to explore on the podium a patient's course of therapy with regard to a defined topic. Six patients are introduced by their therapist in the lecture hall setting. The treating therapists may come from the university outpatient clinic or from hospitals or private practices. Then 6 selected students can explore the previously defined topics about the patient's case directly from the podium. In the following week, the 4 seminars meet separately for debriefing. The objective is to present the collected and processed information and to link theory and practice, including subsequent discussion, case formulation, and consideration of further scientific aspects and issues of patient care of the case that were addressed. The seminar assignment is a written report on the thematic focus, which is prepared jointly by the groups ( 5 students per group) and, in addition to an introduction and discussion, includes the information obtained about the cases presented and discussed in the debriefing (a total of 6 cases).

Content. Prior to the lecture hall exploration, the students only know about the case's diagnostic area and prepare to explore their assigned topic. The group topics to be worked on by 5 students per seminar are presented below. The structure is kept open to the interests of the groups, and the questions serve mainly as a guide:

- Differential diagnosis: Is the diagnosis correct? What are possible (frequent) comorbidities? How would you classify the severity of the case?

- Evidence-based treatment planning: What treatment is indicated? Is the treatment that has been used up to now guideline compliant? What are future goals/ symptom areas, and how should they be treated?

- Psychopharmacology: What psychotropic drugs have already been/are currently being taken? What were the main results, side effects or interactions, rebound phenomena, etc.? In what context was the prescription issued (by a general practitioner, in psychiatry, etc.)? Which psychotropic drugs might be indicated for the disorder? Is there suspected self-medication with psychotropic substances? Additional medication and drug history.

- Relationship dynamics: How successful is the relationship-building in the exploration situation? How does the person describe his/her demeanor in specific social situations (e.g., social skills [Pfingsten and Hinsch, 2007], according to the Kiesler Circle [Kiesler, 1983], etc.)? What sort of social network does the patient have? How have certain people in the patient's biography shaped social situations (e.g., significant others, transference hypotheses [McCullough, 2000])?

- Skill deficits and resilience factors: What are the typical skill deficits characteristic of this disorder? What known resilience factors does this case have (or not have)? More broadly, clarification of changeable risk factors.

- Translation to basic principles: Which basic models and mechanisms are associated with the emergence and maintenance of the disorder, with reference to this specific case? Can these mechanisms be identified in the exploration?

Through this division of topics, the cross-sectional exploration of several cases is presented in a diversified way and an overarching description is suggested, linking the hitherto very diverse theoretical foundations of the subject with practical examples. While the case seminar allows for intensive examination of a specific case treatment, this seminar is intended to provide a vivid picture of the most common types of disorders (e.g., depression, somatoform disorders, anxiety disorders, schizophrenia, obsessive-compulsive disorder, borderline personality disorder, addictions), different treatment settings (inpatient, semiresidential, outpatient), and treatment approaches.

\section{Teaching Evaluations}

The courses we have described are evaluated at regular intervals and are very well received by the students. Fig-
Verhaltenstherapie

DOI: 10.1159/000508273
Wilhelm/Rief/Haberkamp/ von Blanckenburg/Glombiewski 


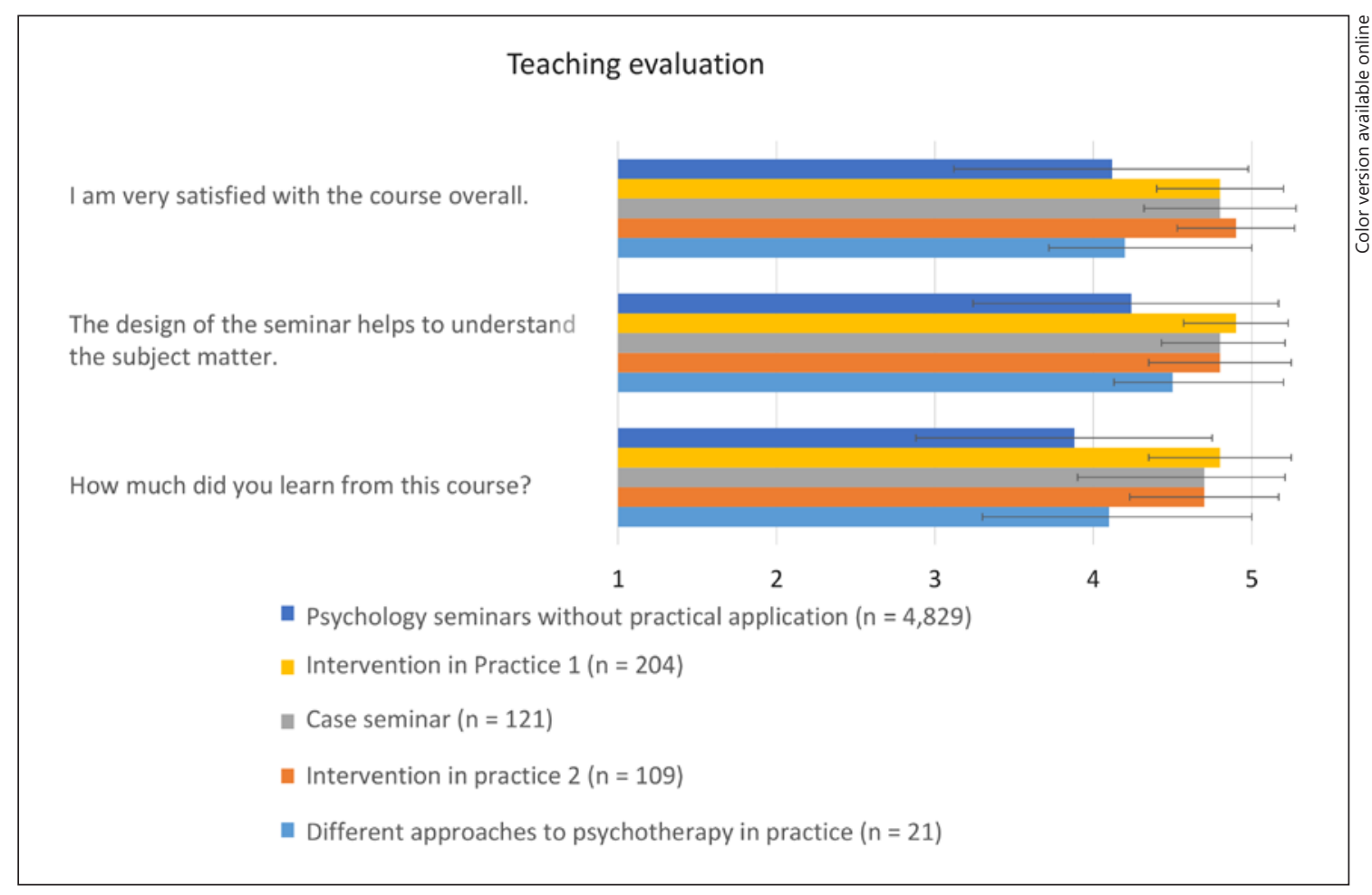

Fig. 4. Random students' teaching evaluations of the seminars. Scale from 1 ("strongly disagree" or "very little”) to 5 ("fully agree" or "very much").

ure 4 shows the students' assessment of the 3 most relevant items for judging the seminar quality (satisfaction, understanding of the material, how much was learned). The items are rated on a 5-point scale from "strongly disagree" $=1$ to "fully agree" $=5$ or "very little" $=1$ to "very much" $=5$. The findings for IP1 comprise 11 teaching evaluations (2012-2019) of 5 teachers. For the case seminar, 8 teaching evaluations (2013-2019) of 4 teachers were included. The assessment of IP2, which has been implemented in Marburg since 2016, comprises the evaluations of 7 tutors who are in psychotherapeutic training. The seminar "Different Approaches to Psychotherapy in Practice" was first introduced in the summer semester of 2019. The evaluation applies to a seminar or a teacher. For comparison, $n=4,829$ teaching evaluations of psychology courses without practical application were shown from the same years.

\section{Discussion of the Teaching Examples}

Difficulties may arise in the implementation of these courses. The most common ones are reported below, along with possible solutions based on the authors' many years of experience.

Introducing a personal problem in the IPs may prove difficult. For example, the selection of problems during the course may be too stressful, despite the preliminary discussion. If that occurs, it is important for the licensed teacher to intervene individually and help to select only a small aspect of the problem or even a completely different problem. Afterwards, it may be necessary to provide support to the students who were "receiving therapy" and to reflect together on the situation in order to discuss deviations from the usual seminar procedure. Sometimes the problems selected turn out to be too complicated or trivial. Here it may help to mention that the problem should be something suitable for training students in the role of therapist. A reminder about the confidentiality of students and teachers concerning the problems being discussed may also prove helpful. If relevance remains questionable, it may be necessary to sharpen the problem slightly.

The case seminar and the "Different Approaches to Psychotherapy in Practice" seminar may raise ethical questions since they involve patients: Is the seminar really helpful, or do patients only participate because of a dependency relationship? Here, the licensed teachers and therapists should critically examine the costs and benefits of participation in a course. As described above, patients with social anxiety disorder or other disorders who benefit from working with a group are often the ones chosen to participate. Case seminars may also cover, for example, additional relapse prevention, systematic repetition of exposure exercises, or social skills training for which the 
Table 1. Comparison of courses and requirements of PsychThApprO

\begin{tabular}{lll}
\hline $\begin{array}{l}\text { Required in PsychThApprO } \\
\text { (ECTS points) }\end{array}$ & $\begin{array}{l}\text { Implementation in Marburg } \\
\text { (ECTS points) }\end{array}$ & Necessary additions \\
\hline BQT II (15) & $\begin{array}{l}\text { Intervention in Practice 1 (4) } \\
\text { Different approaches to psycho- } \\
\text { therapy in practice (2) }\end{array}$ & $\begin{array}{l}\text { Practice of psychotherapy with children and adolescents, including } \\
\text { case seminar and psychotherapy with the elderly } \\
\text { Guidelines for selection options } \\
\text { Selection options for new procedures/neuropsychology } \\
\text { All blocks must contain: }\end{array}$ \\
& $\begin{array}{l}\text { Psychoeducation } \\
\text { Patient education } \\
\text { Explanation of therapy rationale } \\
\text { Therapeutic alliance; counter-regulation } \\
\text { Emergency/crises }\end{array}$ \\
& & $\begin{array}{l}\text { Recognizing one's own emotions; improving self-regulation } \\
\text { Self-reflection (2) }\end{array}$ \\
\hline BQT III outpatient (5) & Case seminar (4) & $\begin{array}{l}\text { If necessary, in tandem with postgraduate psychotherapists in } \\
\text { training }\end{array}$ \\
\hline
\end{tabular}

PsychThApprO, licensing requirements for psychotherapists; ECTS, European Credit Transfer and Accumulation System; BQT, practice-oriented training.

group context is suitable. Systematic evaluations from the perspective of the patient could also be performed in order to exclude or address any possible distress caused by participation in the course. If there is still a need for therapy after the course is finished, when the patients no longer have access to the therapy, the teacher should be available for further contact and could be helpful, if necessary, in arranging for therapy.

One limitation is the validity of the students' teaching evaluations. These are often influenced by the halo effect [Nisbett and Wilson, 1977]. Verified factors here may include, for example, the teacher's charisma [Shevlin et al., 2000] or enthusiasm [Williams and Ceci, 1997], which have a strong impact on how students answer the items about teaching quality. The positive teaching evaluations submitted by students should therefore be viewed with the limitation that many elements of the practical course (e.g., close cooperation in a small group, a great deal of positive feedback among themselves) may distort the concluding assessment of content-related items, such as how much was learned. This would also contribute to explaining why assessments of the seminar "Different Approaches to Psychotherapy in Practice" are somewhat lower than those of the other seminars: first of all, the seminar groups were significantly larger (30 students); second, this was the first time this course was given. It is therefore possible that minor difficulties in communicating the seminar's goals and topics may be seen in the teaching evaluations, which would not occur for a course that had been tried and tested over many years.

The teaching evaluations do not permit us to draw any conclusions about whether the practical skills were actu- ally learned by the end of the course. They primarily show student satisfaction.

\section{Comparison of Teaching Examples and Licensing \\ Requirements (PsychThApprO)}

The PsychThApprO allows for two sections, BQT (practice-oriented training) II and III, in the master's degree program. BQT I is already scheduled in the bachelor's program. In the following paragraphs we match the examples of the Marburg courses to the specifications of the PsychThApprO and describe the proposed adjustments. For a brief overview, see Table 1.

\section{BQT II: In-Depth Practice of Psychotherapy}

BQT II is supposed to include application-oriented courses with exercises in small groups (maximum 15 students). The described procedure of IP1 fits the requirements well:

- Initial conversations, analysis of the problem and goals, as well as treatment planning (included in the Marburg course)

- Basic psychotherapeutic techniques (included)

- Psychoeducation (included)

- Therapy rationale for different approaches and methods (included for behavioral therapy)

- General counseling discussion including participatory decision making (partially included)

- Recognizing, addressing, and solving issues of the therapeutic alliance, problems in treatment, and motivation for change (partially included)

- Recognition of emergencies and crisis situations including suicidality (not included)
Wilhelm/Rief/Haberkamp/ von Blanckenburg/Glombiewski 
In order to adapt IP1 to the requirements of BQT II, all of the above points have to be integrated in a standardized way into the seminar process. IP1 should include triad exercises, especially in participatory decision making and issues of the therapeutic alliance. These issues are currently acknowledged, but only actually practiced when difficulties arise; in most therapeutic dyads, these topics remain unaddressed. The same applies especially to the point on emergencies/crises. In this case, it may be necessary to deviate from the personally introduced problem in IP1; for example, crisis situations could be simulated in role playing.

As far as the diversity of BQT II is concerned, additional courses are needed that will enable psychotherapy to be practiced with children and adolescents. Since this appears to be more difficult to do through role playing, the inclusion of simulated patients and a case seminar with children or adolescents would also be possible. Special features in the treatment of the elderly should also be dealt with explicitly in order to cover the entire life span.

The courses described are strongly influenced by behavioral therapy. Diversity mainly involves newer (third wave) approaches to behavioral therapy. An opening for other scientifically recognized procedures approved by the psychotherapy guidelines therefore seems necessary. The seminar on "Different Approaches to Psychotherapy in Practice" offers the greatest variety in the range of scientifically tested or approved procedures and methods. Practitioners could be invited who use different procedures and methods (e.g., psychodynamic psychotherapy, systemic therapy, behavioral therapy, neuropsychology, client-centered psychotherapy, interpersonal psychotherapy), including for case presentation. The subject areas would then also have to be adjusted: The small groups could work on topics that encompass all the procedures/ methods, as had already been partially planned (relationship dynamics, diagnostic aspects, treatment planning). Additional subject areas could include case formulations, psychoeducation, or treatment rationales. The case seminar and IP2 also in principle allow work with techniques or approaches involving all methods approved in psychotherapy guidelines.

\section{Self-Reflection}

Another requirement of the psychotherapeutic master's program is a unit of at least $60 \mathrm{~h}$ for self-reflection. Here, the students are supposed to learn to reflect on their own psychotherapeutic actions, to recognize their own strengths and weaknesses and the effects of those on their own psychotherapeutic actions, and to be able to accept suggestions for improvement and optimization. Other topics include learning to perceive and regulate one's own emotions (especially perception and self-regulation), cognitions, motives, and behaviors in the thera- peutic process. These are touched upon in the above-described IPs and in the written reports for the case seminar. A sharper focus could be achieved here by selecting the personal problem used in IP2 according to its relevance for future therapeutic work. That way, students playing the role of therapist could gain valuable experience as before, and students in the role of patient could also benefit from the self-reflection. In order to ensure self-reflection that is professional and as instructive as possible, the experienced, licensed teachers should be more involved in the work on the personal problem. For example, there could be a second period of office hours after the IP2, in which the students reflect on the knowledge they have gained from the triad exercises and work out specific "take home messages". At the same time, it should be borne in mind that the openness of university students may be limited. Such consultation should therefore serve more as preparation for the self-awareness envisaged in further training.

\section{BQT III: Applied Practice of Psychotherapy}

In BQT III, the skills acquired in BQT II should be deepened in real treatment settings (outpatient and inpatient). The case seminars described above under "Examples" already meet one requirement for the outpatient component, namely participation in psychotherapeutic outpatient treatment for at least 12 consecutive hours. The required minimum of 3 basic measures (relaxation procedures, psychoeducation, and informational conversations with relatives) can be included here as a standard feature. The outpatient BQT III omponent gives the student 5 ECTS (European Credit Transfer and Accumulation System) points (corresponding to $150 \mathrm{~h}$ ); a case seminar gives 4 ECTS points. There are $30 \mathrm{~h}$ left that can be used, for example, for supervised initial interviews, medical histories, risk assessments, etc. The remaining patient contacts required by BQT III must therefore be fulfilled in the inpatient component (15 ECTS points/450 h).

\section{Outlook}

New formats of practical teaching are required with the change in the law towards a psychotherapeutic master's program that gives the student a license directly. The courses presented here fulfill the requirements for high-quality teaching in psychology [Spinath et al., 2018] and are also very well received by students. Comparing the previous licensing requirements, we see that numerous points are already covered by the courses (notably by teaching psychotherapeutic skills to healthy people, with simulated and pathological problems).

A big future challenge for university teaching will be preparation for the planned "application-oriented par- 
cours exam" as part of the PsychThApprO. This exam was designed on the model of the "Objective Structured Clinical Examination" [Harden et al., 1975]. It consists of 5 stations ( 30 min each), each of which uses trained simulated patients. The students move through the stations in groups of 5 . The following topics should be examined in practice:

- Patient safety (e.g., risk assessment, suicide risk or other self-harm, prognostic risk factors including adjustments to the treatment plan)

- Shaping the therapeutic alliance (e.g., recognizing problems in the relationship and intervening if necessary)

- Diagnostics (also recommendations for treatment setting)

- Patient information and education (especially informed consent, contribution to independent patient decisions)

- Guideline-oriented treatment recommendations (including recognizing when no psychotherapeutic treatment can be recommended or when further treatment by third parties is necessary)

The students must therefore be trained in even more detail in basic psychotherapeutic skills, and the translation of theoretical knowledge to practice must be promoted more intensively. In addition to the role playing the students have used with each other so far, this also offers the teaching option of work with simulated patients. Thus, the methods described could be combined into a kind of parcours revision course. There could be a structure similar to that of IP2: the students practice certain types of skills with one another in small groups and meet with psychotherapists in training or in continuing education who already have experience in patient contact, with whom the exercises are deepened. Video feedback could be used to discuss content as well as appearance and conversation techniques, in a detailed and rigorous manner, with the supervising teacher.

The awarding of a license after completing a master's degree in psychotherapy is a challenge for university teaching, while simultaneously offering great opportuni- ties for application- and skill-oriented studies. If these opportunities are utilized, care for people with mental illnesses can benefit. This means that new practical courses must be created or existing teaching concepts must be further developed and adapted to the new licensing requirements. The concepts presented here provide points of reference for how to approach these new requirements and should stimulate ideas and creativity to develop similar teaching concepts.

\section{Acknowledgment}

Our sincere thanks go to all our colleagues who have worked tirelessly in recent years to continuously improve and develop new teaching concepts. We thank, in alphabetical order, Prof. Dr. EvaLotta Brakemeier, PD Dr. Bettina Doering, Prof. Dr. Cornelia Exner, Dr. Japhia Gottschalk, Dr. Kristina Klaus-Schiffer, PD Dr. Maria Kleinstäuber, Dr. Kerstin Kühl, Prof. Dr. Tania Lincoln, Dr. Rainer Lutz, Prof. Dr. Bernd Röhrle, Dr. Christa Schulze, Prof. Dr. Gert Sommer, Dr. Cornelia Weise.

\section{Statement of Ethics}

No examination by an ethics committee was necessary for this review article.

\section{Conflict of Interest Statement}

The authors declare that there are no conflicts of interest and no financial assistance with regard to the present work.

\section{Author Contributions}

Marcel Wilhelm wrote the first version of the manuscript. Julia Glombiewski and Winfried Rief contributed to the final article with additions and changes based on their many years of teaching experience. Anke Haberkamp assisted in the conception and structure of the article. Pia von Blanckenburg also scored the teaching evaluations.

\section{References}

Brakemeier EL, Normann C. Praxisbuch CBASP Behandlung chronischer Depression. Weinheim: Beltz; 2012.

Ellis A. Reason and emotion in psychotherapy. New York: Lyle Stuart; 1962.

Greenberg LS. Emotion-focused therapy. Clin Psychol Psychother. 2004;11(1):3-16.

Harden RM, Stevenson M, Downie WW, Wilson GM. Assessment of clinical competence using objective structured examination. BMJ. 1975 Feb;1(5955):447-51.
Hayes S, Strosahl K, Bunting K, Twohig M, Wilson $\mathrm{K}$. What is acceptance and commitment therapy? In: Hayes S, Strosahl K, editors. A practical guide to acceptance and commitment therapy. Berlin: Springer; 2004. https:// doi.org/10.1007/978-0-387-23369-7_1.

Kiesler DJ. The 1982 Interpersonal Circle: A taxonomy for complementarity in human transactions. Psychol Rev. 1983;90(3):185-214.

Leahy RL. Cognitive therapy techniques: a practitioner's guide. New York: Guilford Press; 2017.
Linehan MM. Cognitive behavioral therapy of borderline personality disorder. New York: Guilford Press; 1993.

McCullough JP. Treatment of chronic depression: Cognitive Behavioral Analysis System of Psychotherapy. New York: Guilford Press; 2000.

Nisbett RE, Wilson TD. The halo effect: evidence for unconscious alteration of judgments. J Pers Soc Psychol. 1977;35(4):250-6. 
Persons J. The case formulation approach to cognitive-behavior therapy. New York: Guilford Press; 2008.

Pfingsten U, Hinsch R. Gruppentraining sozialer Kompetenzen (GSK): Grundlagen, Durchführung, Materialien. Weinheim: Beltz; 2007.

Reinmann G, Mandl H. Unterrichten und Lernumgebungen gestalten. In: Krapp A, editor. Pädagogische Psychologie. Weinheim: Beltz; 2006. pp. 601-46.

Schauer M, Neuer F, Elbert T. Narrative exposure therapy: a short-term treatment for traumatic stress disorders. Bern: Hogrefe Publishing; 2011.
Schmidt B, Tippelt R. Besser Lehren - Neues von der Hochschuldidaktik? Z Pädagogik. 2005; 50:103-14.

Shevlin M, Banyard P, Davies M, Griffiths M. The validity of student evaluation of teaching in higher education: love me, love my lectures? Assess Eval High Educ. 2000;25(4):397-405.

Solga M, Ryschka J, Mattenklott A. Personalentwicklung: Gegenstand, Prozessmodell, Erfolgsfaktoren. In: Ryschka J, Solga M, Mattenklott A, editors. Praxishandbuch Personalentwicklung: Instrumente, Konzepte, Beispiele. Wiesbaden: Springer Gabler; 2011. p. 19-34.
Spinath B, Antoni C, Bühner M, Elsner B, Erdfelder E, Fydrich T, et al. Empfehlungen zur Qualitätssicherung in Studium und Lehre. Psychol Rundsch. 2018;69(3):183-92.

Tonhäuser C, Büker L. Determinants of transfer of training: a comprehensive literature review. Int J Res Vocat Educ Train. 2016;3(2): 127-65.

Williams WM, Ceci SJ. “How'm I doing?” Problems with student ratings of teachers and courses. Chang Mag High Learn. 1997;29(5): 12-23. 